\title{
Dış Mekân Odaklı Bir Yaratıcı Drama Uygulama Örneği: Ulucanlar Cezaevi'nden Açık Okul'a
}

\author{
O. Nejat AKFIRAT ${ }^{1}$ Ö. Özlem GÖKBULUT ${ }^{2}$ Oylum AKKUŞ ${ }^{3}$
}

\begin{abstract}
Özet
Yaratıcı dramanın bileşenleri incelendiğinde lider/eğitmen, grup ve mekan olduğu görülmektedir. Bu çalışma da adı geçen bileşenlerden mekan ve özellikle dış mekanda yapılan yaratıcı drama çalışmalarından birini örneklemek amaçlanmıştır. Çalışma 2007 Haziran ayında Mimarlar Odası'nın düzenlediği bir festival kapsamında Ulucanlar Cezaevi'nde gerçekleştirilmiştir. Dış mekan olarak Ulucanlar Cezaevi'nin seçilmesinde hem festivalin amacının hem de bu cezaevinin tarihi öneminin yeri vardır. Çalışmaya avukat ve sıradan vatandaşlardan oluşan 22 kişi katılmıştır. Ulucanlar Cezaevi'ni bir Açık Okul'a nasıl dönüştürürüz temasından hareketle hazırlanan iletişim etkileşim çalışmalarını içeren yaratıcı drama atölyesi 6 saat sürmüştür. Atölye öncesinde ve sonrasında sorulan sorulardan hareketle katılımcıların Açık Okul'a dair yaratıcı fikirler ortaya attıkları söylenebilir.
\end{abstract}

Anahtar Sözcükler: Yaratıcı drama, Ulucanlar Cezaevi, Açık Okul

\section{An Outdoor Focused Drama Case Study: From Ulucanlar Prison to Open School}

\section{O. Nejat AKFIRAT ${ }^{4}$ Ö. Özlem GÖKBULUT ${ }^{5}$ Oylum AKKUŞ ${ }^{6}$}

\begin{abstract}
The components of creative drama can be classified into three sections; leader/teacher, group, and the locality. In this study it was aimed to give an example to one of the creative drama applications focusing on outside locality. This study was carried out in June, 2007 by the researchers at Ulucanlar Prison. It was one of the activity in the festival wihch was organized by Architecture Association in Ankara. The locality Ulucanlar Prison has a rich history and amazing architectural construction. A group of attorneys and citizens including 22 people were involved in this study. Six-hour creative drama workshop was conducted with the participants under the them of "How can we construct an Open School from Ulucanlar Prison". The participants suggested creative ideas related with the theme.
\end{abstract}

Keywords: Creative drama, Ulucanlar Prison, Open School

\footnotetext{
${ }^{1}$ Çağdaş Drama Üyesi

2 Çağdaş Drama Üyesi

${ }^{3}$ Çağdaş Drama Üyesi

${ }^{4}$ Çağdaş Drama Üyesi

${ }^{5}$ Çağdaş Drama Üyesi

${ }^{6}$ Çağdaş Drama Üyesi
} 


\section{Giriş}

Eğitim sistemi içinde gerek ilköğretim programlarında gerekse yükseköğretim programlarında yaratıcı drama etkin öğrenme yöntemlerinden biri olarak öğreneni merkeze alan bir öğrenme yöntemi olarak yerini almıştır. Yaratıcı drama genel olarak bir olayı, kavramı, olguyu, işlemek için grubun geçmiş yaşantılarından yola çıkarak drama tekniklerini kullanarak oyunsu süreç içerisinde yapılan canlandırmalar olarak tanımlanmaktadır (Adıgüzel, 2006). Yaratıcı dramanın bileşenleri incelendiğinde temel öğelerin lider, grup ve mekan olduğu görülmektedir (Adıgüzel, 2006). Mekanın neresi olduğu, açık ya da kapalı oluşu, büyüklüğü, aydınlatması gibi değişik etmenler yaratıcı drama çalışmalarında etkilidir. Özellikle mekanın odakta olduğu çalışmalara bakıldığında mekan olarak genellikle müzenin seçildiği görülmektedir (Earl, 1995). Bunun yanı sıra çeşitli uygulamalarda bir sokağı ve o sokağın sakinlerini tanımak için sokakta yapılan yaratıcı drama çalışmaları, bir üniversite yerleşkesinde yapılan çalışmalar da göze çarpmaktadır [1].

Yaratıcı dramanın kültür pedagojisi ve sanat eğitiminde de rolü vardır (İlhan-Çakır, 2007). Kültür pedagojisi bağlamında yaratıcı drama incelendiğinde kültüre dair değerleri korumak, kültürün içinde yer alan konuları incelemek adına yaratıcı drama vazgeçilmez bir yöntemdir.

Bu çalışmanın amacı Ulucanlar Cezaevi'ni daha etkin kullanmak için Mimarlar Odası'nın düzenlediği bir festival kapsamında yeni fikirlerin ortaya çıkmasını sağlamaktır. $\mathrm{Bu}$ amacı gerçekleştirmek için Ulucanlar Cezaevi yaratıcı drama çalışmaları için dış mekan olarak seçilmiştir. 2006 Ağustos ayından beri boş olan Ulucanlar Merkez Kapalı Cezaevi tarihi ve mimari açıdan oldukça zengindir. Çalışma Mimarlar Odası'nın düzenlediği bir festival kapsamında gerçekleştirilmiştir. Mimarlar Odası Ulucanlar Cezaevi'nin mimari yapısını koruyup geliştirmek ve onu alışveriş merkezi haline getirmek yerine bir kültür merkezi haline getirmeyi planlamaktadır. Bu kapsamda yer alan çalışmalardan biri olarak ta yaratıcı drama çalışması yapılmıştır.

6 saatlik yaratıcı drama atölyesi cezaevinin avlusu ve salonunda gerçekleştirilmiştir. Çalışmayı yürüten araştırmacılardan ikisi önceden katılımcı belirlemeden uygulama gününün sabahı oraya giderek kapıda çalışmanın amacını anlatarak gönüllü aramışlardır. Bu arayış sonunda çalışmaya avukat ve sıradan vatandaşlardan oluşan toplam 22 kişi katılmıştır.

Çalışmaya başlamadan önce katılımcılara "Ulucanlar" denince aklınıza neler geliyor, çalışmanın sonunda ise "Açık Okul" denince aklınıza neler geliyor soruları sorulmuş ve katılımcılarla beraber her ikisi için çağrışım zinciri oluşturulmuştur. Atölyenin içeriğini 1sınma-canlandırmadeğerlendirme aşamalarına uygun () iletişim-etkileşim çalışmaları oluşturmaktadır. Doğaçlamaların amacı katılımcıların mekanla ve bu mekanda yaşayanlarla duygudaşlık kurmalarını sağlamaktır. Çalışmanın sonunda katılımcılara bu mekanı Açık Okul'a dönüştürecek bir tasarım yapsalar neler yapabilecekleri sorulmuştur. Bu tasarımın yapılması için aşağıdaki katılımcıların gruplar halinde çalışarak aşağıdaki soruları yanıtlamaları gerekmektedir.

Mekan için slogan ne olur?

Katılimcisl kimlerdir?

Bu kurumun amaçları nelerdir?

Eğitimci kadrosu kimlerden oluşur?

Eğitim süresi ne kadardır?

Eğitimde kullanılan yöntem ve teknikler nelerdir?

Mekanin düzenlenmesi nasıl yapılır?

Katılımcıların Açık Okul tasarımlarına bir grubun örneği şöyle olmuştur;

GÖKKUŞA $\breve{G I} A C ̧ I K$ OKULU

Mekan için slogan ne olur? Yaşama Bağlan 


\section{Katılımcısı kimlerdir? Herkes}

Bu kurumun amaçları nelerdir? Huzur ve mutluluk sağlama, özgür düşünceyi geliştirme, suçu engelleme, farkındalık artırma, yaratıcılığı ve üreticiliği geliştirme, geçmişi hatırlama

Ĕ̈itimci kadrosu kimlerden oluşur? Sanatçı, zanaatçı, eğitimci gibi profesyoneller

Eğitim süresi ne kadardır? Yaşam boyu

Eğitimde kullanılan yöntem ve teknikler nelerdir? Yaratıcı drama, deney, forum, yazılı, sözlü, görsel anlatım.

Mekanın düzenlenmesi nasıl yapılır? Mekanın özgün hali bozulmadan hem müze hem de atölyeler olarak kullanılmalıdır.

Bunun yanı sıra Ulucanlar hakkında katılımcıların çalışma başında yazdıkları düşünceler ise aşağıdaki gibi özetlenebilir.

"Acıların tutsaklı̆̆ı mekanı"

"Belki cezadan öte hayat söndüren bir mekan

"Ylllarca önünden geçip de hep merak ettiğim bir yerdi. İlk defa bir hapishanenin bahçesindeyim çok merak ediyorum."

"Ulucanlar'a yıllarca avukat olarak tutuklu müvekkillerimle görüşmek için gelmiştim. Olağanüstü güvenlik uygulamaları, yoğun aramalar, bir yandan sizden duyacağı bir iki güzel umut vaad eden söze kendini kendini adayan insanlart ve izbeliği görmüşı̈̈m."

Çalışmanın sonunda ise katılımcılar aşağıdaki görüşleri belirtmiş̧lerdir.

"Bir zamanlar tarihe tanıklık etmiş bu yerin müze olarak halka açılması, insanlara verilecek eğitimle tutsaklı̆̆ı özgürlüğe dönüşmesi bilinç ve yaratıcıllğın mekanı olmasını özlemle düşlüyor ve bekliyoruz."

"Hayal ettiğimden daha kötü buldum. Bu yerlerin ortadan kaldırllmasinda emek sarf etmek için gönüllü çalışacağım. İnsanların üretebileceği, kendini geliştiren estetik duygusu ve düşüncelerinin kisıtlanmadiğ bir okul, sinırsız ĕgitim"

"Bugün Yaratıcı drama atölyesi için yine geldik. Bina aynıydl. Sadece girişte eski uygulamalara maruz kalmadık. Ayrı bir gözle tüm cezaevini gezdik. Yeni kavramlara ulaştık. O kavramlar bizi Açıl Okul düşüncesine ulaştırdı. Umarım "Açık Okul” düş olmaktan çıkıp gerçek olur."

Çalışma başında ve sonundaki düşünceler, ayrıca katılımcıların grup olarak yaptıkları Açık Okul tasarımları incelendiğinde grubun mekana karşı farkındalığının arttığı, mekanın açık okul olarak tasarlanmasında rol oynamak istediği geçirdiği yaratıcı drama atölyesi sonrasında söylenebilir.

Mimarlar Odası ve Ankara Barolar Birliği'nin katkılarıyla yapılan bu festival sonrasında Ulucanlar Merkez Kapalı Cezaevi alışveriş merkezi haline getirilmekten vazgeçilmiş ancak hala bir açık okula ya da müzeye dönüştürülmemiştir. Bu konuda sivil toplum örgütlerinin yeni bir festival düzenleme ya da kamuoyu oluşturma gibi olası katkılarının vazgeçilmez olduğu düşünülmektedir. Ayrıca bir mekanı tanımak ve içselleştirmek adına yaparak yaşayarak öğrenmeye olanak tanıyan yaratıcı drama çalışmalarının özellikle tarihi mekanları tanıma konusunda yaygınlaştırılması önerilmektedir.

\section{KAYNAKLAR}

Adıgüzel, H. Ö. (2006). Yaratıcı drama kavramı, bileşenleri ve aşamaları. Yaratıcı Drama Dergisi, $1,1,17-31$.

Earl, A. (1995). Müze pedagojisi İngiltere'de nasıl gelişti? Drama Maske Müze, Edit: San, İ. İşkur Matbaac1lik: Ankara. 
İlhan-Çakır, A. (2007). Yaratıı drama ile örtüşen çağdaş sanat akımları. Yaratıcı Drama Dergisi, 1, 3-4, 139-155.

[1] Çağdaş Drama Derneği, Liderlik Eğitmenlik Programı, 4. Aşama Yayınlanmamış Ders Notları. 